\title{
Aspectos atuais da relação entre exercício físico, estresse oxidativo e magnésio
}

\author{
Current aspects of the relationship between physical \\ exercise, oxidative stress and magnesium
}

Este trabalho visa a contribuir com informações atualizadas sobre a relação entre exercício, estresse oxidativo e magnésio. São escassos os trabalhos que discutem a produção de radicais livres nesse contexto. A deficiência de magnésio altera a fluidez das membranas celulares e mitocondriais e promove perturbações na homeostase do cálcio e na atividade das defesas antioxidantes. No exercício, a falta de magnésio nos tecidos musculares os torna mais suscetíveis à infiltração de macrófagos e neutrófilos e ao rompimento do sarcolema, dificultando o processo de regeneração e podendo ocasionar queda no desempenho físico. Conclui-se que o papel metabólico da deficiência de magnésio no estresse oxidativo induzido pelo exercício deve ser mais pesquisado, focalizando os seus efeitos na musculatura esquelética em indivíduos que praticam exercício regular e na deficiência marginal de magnésio.

Termos de indexação: Deficiência de magnésio. Estresse oxidativo. Exercício. Magnésio.

\section{A B S T R A C T}

This article contributes to updated information about the relationship between exercise, oxidative stress and magnesium. There are few studies that discuss free radical production in this context. Magnesium deficiency alters cellular and mitochondrial membrane fluidity and promotes disturbances on calcium homeostasis and on the activity of antioxidant defenses. During exercise, lack of magnesium in muscle tissue turns them more susceptible to macrophage and neutrophil infiltration and to sarcolema damage, impairing the regeneration process and leading to decreased physical performance. In conclusion, the metabolic role of magnesium deficiency on exercise-induced oxidative stress should be further researched, focusing on its effects on skeletal muscle in individuals who practice regular physical exercise and in marginal magnesium deficiency.

Indexing terms: Magnesium deficiency. Oxidative stress. Exercise. Magnesium.

\footnotetext{
1 Universidade Federal do Maranhão, Curso de Nutrição, Departamento de Ciências Fisiológicas. São Luís, MA, Brasil.

2 Universidade de São Paulo, Faculdade de Ciências Farmacêuticas, Departamento de Alimentos e Nutrição Experimental. Av. Professor Lineu Prestes, 580, 05508-900, Butantã, São Paulo, SP, Brasil. Correspondência para/Correspondence to: J. TIRAPEGUI. E-mail: <tirapegu@usp.br>
} 


\section{N T R O D U ÇÃ O}

Atualmente é reconhecido que os radicais livres, além de serem um dos fatores que causam lesões no exercício físico, também exercem efeitos positivos no sistema imunológico e em funções metabólicas essenciais'. Se a ação de tais radicais livres será benéfica ou deletéria para o organismo vai depender da atividade dos antioxidantes, que são substâncias que suprimem tais radicais e seus efeitos danosos. O estresse oxidativo acontece quando a ação dos radicais livres supera a atividade dos antioxidantes ${ }^{2}$. Uma das principais conseqüências do estresse oxidativo é a peroxidação lipídica, além de possíveis danos a proteínas e ao DNA (ácido desoxirribonucléico), alterando conseqüentemente a função celular³.

A atividade física aumenta tanto a produção de radical livre como a utilização de antioxidantes. A alimentação é responsável pelo fornecimento dos antioxidantes. A deficiência dietética de antioxidantes e de outras substâncias essenciais pode causar estresse oxidativo ${ }^{4}$. Dentre tais substâncias está o magnésio, mineral que participa do metabolismo energético, da regulação dos transportadores de íons e da contração muscular ${ }^{5}$.

A deficiência dietética de magnésio é positivamente correlacionada ao aumento da peroxidação lipídica e à diminuição da atividade antioxidante ${ }^{6}$. Entretanto, até o momento, pouco tem sido discutido a respeito do seu efeito sobre o metabolismo oxidativo durante a atividade física. O objetivo deste trabalho é contribuir com informações atualizadas a respeito da relação entre exercício físico, estresse oxidativo e magnésio.

\section{Produção de radicais livres no exercício físico}

A molécula de $\mathrm{O}_{2}$ (oxigênio) contém dois elétrons desemparelhados com spins paralelos. A redução univalente de oxigênio, um processo de significância biológica para a produção de energia, trata da redução de um elétron por vez. Tal processo leva à produção de radicais livres, apresen- tando um ou mais elétrons desemparelhados, que são capazes de existir livremente, podendo reagir com estruturas biológicas e outros componentes, causando danos oxidativos e produzindo outras espécies reativas de oxigênio (ERO) 7 .

Durante o exercício físico, tanto a atividade aeróbia quanto anaeróbia podem aumentar, respectivamente, 20 e 50 vezes o consumo energético do tecido muscular. Especialmente no exercício aeróbio, o fluxo de oxigênio no músculo esquelético aumenta em cerca de 100 vezes e o fluxo sangüíneo em 30 vezes. Na passagem do estado de repouso para o exercício, nenhum outro tecido, além do muscular, é capaz de sofrer tamanha mudança quanto ao consumo de oxigênio. Assumindo que uma porcentagem fixa deste oxigênio ( $1 \%$ a $2 \%$ ) é reduzida a radical superóxido $\left(\mathrm{O}_{2}^{-}\right)$, a musculatura exercitada é uma fonte geradora em potencial de ERO ${ }^{8}$.

No exercício físico, as espécies reativas de oxigênio e as espécies reativas ao nitrogênio (ERN) são as mais estudadas. As ERN podem ser formadas por reações com ERO ou podem aumentar a produção das mesmas. Os radicais superóxido $\left(\mathrm{O}_{2}^{-}\right)$, peróxido de hidrogênio $\left(\mathrm{H}_{2} \mathrm{O}_{2}\right)$ e óxido nítrico $\left(\mathrm{NO}^{*}\right)$ reagem rapidamente com apenas algumas moléculas, enquanto o hidroxil $\left(\mathrm{OH}^{\bullet}\right)$ reage rapidamente com qualquer composto. Espécies como os radicais peroxil $\left(\mathrm{RO}_{2}{ }^{\circ}\right)$, alcoxil $\left.(\mathrm{RO})^{*}\right)$, ácido hipocloroso $(\mathrm{HOCl})$, dióxido de nitrogênio $\left(\mathrm{NO}_{-2}\right)$ e peroxinitrito (ONOO-) apresentam reatividade intermediária4.

Até recentemente, acreditava-se que a síntese de radicais livres na atividade física tinha apenas efeitos deletérios para o organismo. Hoje, é reconhecido que baixos níveis de radicais livres presentes na musculatura em repouso podem sinalizar etapas da contração normal. As espécies reativas de oxigênio e de nitrogênio modulam vários elementos da função celular, como captação de glicose, metabolismo mitocondrial, transcrição gênica e catabolismo muscular. Tais metabólitos ainda têm complexos efeitos autócrinos/parácrinos nos componentes celulares que regulam a contração9. 
A cadeia transportadora de elétrons mitocondrial é considerada a principal fonte de radicais livres no exercício aeróbio. Vários dos centros de oxirredução existentes nos quatro complexos enzimáticos que compõem a cadeia respiratória podem ser oxidados por oxigênio molecular, resultando na formação de radical superóxido ${ }^{10}$.

Outro mecanismo considerado responsável pela produção de radicais livres no exercício é o processo de isquemia-reperfusão. Em exercícios realizados em intensidade acima do $\mathrm{VO}_{2 m a ́ x}$ O tecido muscular pode sofrer hipóxia, pela falta de circulação sangüínea após repetidas contrações (isquemia). A reoxigenação destes tecidos logo depois do rápido aumento no fluxo sangüíneo (reperfusão) pode levar à produção de radicais livres $^{11,12}$. Esta isquemia, seguida de reperfusão causada pelo exercício intenso, promove a conversão de xantina desidrogenase (XD) em xantina oxidase $(\mathrm{XO})$ e forma radical superóxido como subproduto final da reação ${ }^{11}$.

Alterações no metabolismo muscular causadas por dano celular subseqüente ao estresse oxidativo sinalizam uma resposta inflamatória, na qual células fagocitárias - neutrófilos, principalmente - se infiltram no tecido danificado ${ }^{3}$. Tais neutrófilos produzem a enzima NAD(P)H oxidase, que catalisa a produção de radical superóxido usando $\mathrm{NAD}(\mathrm{P}) \mathrm{H}$ como doador de elétron. $\mathrm{A}$ $N A D(P) H$ oxidase também participa de células não fagocíticas, produzindo radical superóxido como sinalizador intracelular ${ }^{13}$. Os neutrófilos produzem ainda mieloperoxidase (MPO), que catalisa a conversão de peróxido de hidrogênio em ácido hipocloroso ${ }^{10}$.

O óxido nítrico é sintetizado a partir da molécula de oxigênio e L-arginina pela enzima óxido nítrico sintase (NOS). A musculatura esquelética expressa a isoforma neuronal da NOS (nNOS), localizada próximo ao sarcolema. A isoforma endotelial (eNOS) está presente em estruturas vasculares adjacentes 9 . A NOS tem maior atividade nas fibras musculares do tipo llb, glicolíticas, do que nas do tipo I, oxidativas. Assim, a atividade da NOS é mais proeminente nos exercícios anaeróbios. Uma alta produção de óxido nítrico durante a contração dá início a uma cadeia de reações produtoras de radicais livres, a partir da qual o óxido nítrico interage com o radical superóxido para gerar peroxinitrito ${ }^{14}$.

As ciclooxigenases (COX) catalisam as etapas iniciais da conversão do ácido araquidônico (AA) no intermediário prostaglandina $\mathrm{H}_{2}$, que, por sua vez, é convertida em prostaglandinas e tromboxanas, dando início às respostas inflamatórias. A partir desta cascata de reações, as COX também produzem espécies reativas de oxigênio².

Outros processos relacionados com a produção de radicais livres no exercício envolvem a oxidação de componentes da hemoglobina e da mioglobina, as catecolaminas, a elevação da temperatura corporal e o ácido lático, que é capaz de converter radical superóxido em hidroxila² .

\section{Os mecanismos de defesa antioxidantes no exercício físico}

Um antioxidante pode ser definido como qualquer substância que, presente em baixas concentrações frente a um substrato oxidável, retarda ou previne a oxidação de tal substrato ${ }^{4}$. Os antioxidantes protegem o organismo inibindo as reações ligadas à formação de radicais livres, impedindo a perda da integridade celular e, ainda, reparando as lesões causadas por tais compostos. Diversas substâncias fisiológicas enzimáticas e não enzimáticas são reconhecidas como antioxidantes. Os antioxidantes não enzimáticos consistem principalmente de glutationa (GSH) e ceruloplasmina. Os antioxidantes dietéticos exógenos (vitaminas $\mathrm{C}$ e $\mathrm{E}, \beta$-caroteno, $\mathrm{Cu}$, Se, $\mathrm{Zn}$, ubiquinona e flavonóides) interagem com os antioxidantes endógenos compondo uma rede celular antioxidante integrada. Já os antioxidantes enzimáticos são representados por superóxido dismutase (SOD), glutationa peroxidase (GPx), glutationa redutase (GR) e catalase (CAT) ${ }^{7}$. 
A superóxido dismutase tem como função catalisar a conversão do superóxido em peróxido de hidrogênio, que é transformado em água por ação de catalases e peroxidases. Já a glutationa peroxidase é a enzima responsável pela redução de peróxido de hidrogênio em água. O resultado da reação enzimática é a oxidação da glutationa em glutationa oxidada (GSSG). Já a GSSG é reduzida a glutationa pela reação enzimática dependente de nicotinamida adenosina dinucleotídeo fosfato hidrogenado (NADPH) catalisada pela glutationa redutase. Tanto a glutationa peroxidase como a glutationa redutase atuam no citossol e na mitocôndria. A catalase, assim como a glutationa peroxidase, decompõe peróxido de hidrogênio, que é utilizado na oxidação de diversos doadores de hidrogênio, tais como metanol e etanol ${ }^{7}$. Do contrário, o peróxido de hidrogênio se combina diretamente com o Fe, na forma iônica $\mathrm{Fe}^{2+}$, na chamada reação de Fenton. A atividade de superóxido dismutase, catalase e glutationa peroxidase é maior em músculos com alta capacidade oxidativa (fibras musculares do tipo I) em comparação a músculos com baixa capacidade oxidativa (com predominância de fibras musculares do tipo $l l b)^{1}$.

\section{Dano muscular e exercício físico}

Logo após o exercício físico, o músculo apresenta um micro dano que tem início no nível de miofibrilas. Caso não tenha um tempo mínimo para recuperação antes de uma subseqüente sessão de exercício, o tecido muscular pode continuar sendo danificado, o que pode, inclusive, levar à apoptose (morte celular programada) ${ }^{15}$.

No tecido muscular, sob influência de maiores concentrações de radicais livres, o retículo sarcoplasmático libera íons de cálcio em maior quantidade no sarcoplasma, aumentando a sua concentração intracelular ${ }^{14}$. As concentrações de ferro intracelular também aumentam, dando mais chance deste reagir com os radicais livres ${ }^{4}$. A presença de radicais livres no músculo inativa suas enzimas, especificamente aquelas envolvidas no metabolismo energético. O óxido nítrico, em particular, pode diminuir a capacidade contrátil muscular por inibir a atividade da ATPase dependente de cálcio do retículo sarcoplasmático e por induzir a hiperpolarização do potencial de membrana. A diminuição da atividade das ATPases dificulta a ação das proteínas contráteis (actina e miosina), diminuindo, assim, o mecanismo de contração muscular².

O dano muscular após o exercício físico pode ser caracterizado pelo aumento das concentrações de diversas substâncias, tais como as reativas ao ácido tiobarbitúrico (ThioBarbituric Acid Reactive Substances - TBARS), malondialdeído (MDA) ou, ainda, dienos conjugados. O aumento das concentrações plasmáticas de proteínas, como a creatina quinase (CK) e a lactato desidrogenase (LDH), é importante por refletir se houve ou não rabdomiólise e, conseqüentemente, saída destas do músculo danificado ${ }^{14}$. Outros indicadores utilizados determinam a atividade de enzimas antioxidantes, os produtos da oxidação de proteína e de DNA. O procedimento mais adequado para avaliação do estresse oxidativo é fazer uso de mais de um método, devido à complexidade deste fenômeno².

Especialmente com o treinamento físico regular, as células musculares se adaptam a um eventual incremento na produção de radicais livres, com o aumento da ação dos mecanismos de proteção citados anteriormente, reduzindo assim o surgimento de lesões. Enquanto a atividade física exaustiva aumenta o dano oxidativo, a atividade física moderada pode reduzir a ação do estresse oxidativo sobre os tecidos ${ }^{14}$.

De fato, a literatura não tem sido consistente na demonstração do dano muscular como resultado do estresse oxidativo induzido pelo exercício. A variabilidade dos resultados encontrados depende do tipo de exercício (intensidade e duração), dos indivíduos estudados (treinado ou destreinado; humano ou animal), do seu estado nutricional e dos métodos de determinação de estresse oxidativo ${ }^{14}$. Sureda et al. ${ }^{16}$ observaram no sangue de ciclistas profissionais após percor- 
rerem $172 \mathrm{~km}$ o aumento significativo na atividade da catalase de eritrócitos e na atividade da mieloperoxidase (MPO) em neutrófilos após o exercício, bem como maior concentração de malondialdeído plasmático e eritrocitário. Houve também hemólise induzida pelo exercício prolongado. Conclui-se que concentrações maiores de malondialdeído no eritrócito se deram em função da alta produção de peróxido de hidrogênio a partir da oxidação do grupo heme. Já no plasma o incremento de MDA estaria relacionado ao ácido hipocloroso proveniente da maior atividade da mieloperoxidase. Em outro estudo, Uchiyama et al. ${ }^{12}$ verificaram que a concentração de creatina quinase no soro de ratos após uma sessão de levantamento de peso foi maior após o exercício, assim como as concentrações de superóxido dismutase, catalase e glutationa peroxidase nos músculos sóleo e plantaris. Análises histológicas do tecido muscular apontaram ainda a infiltração de macrófagos no tecido. Esses resultados sugerem que realmente houve dano muscular após o exercício provocado pelo estresse oxidativo.

\section{Importância biológica do magnésio}

O magnésio é um mineral importante em várias reações celulares, participando de quase todas as ações anabólicas e catabólicas. Cerca de 300 sistemas enzimáticos são dependentes da presença de magnésio. Algumas destas atividades incluem a glicólise e o metabolismo protéico e lipídico ${ }^{17}$. O magnésio é importante tanto na geração de energia aeróbia quanto anaeróbia, indiretamente, como complexo Mg-ATP, ou diretamente, como um cofator enzimático ${ }^{5}$. Aliás, foi assinalado o efeito da deficiência de magnésio na redução da integridade e da função das membranas celulares, bem como na patogênese de diversas doenças, tais como cardiovascular, pré-eclâmpsia/eclâmpsia, derrame, hipertensão, diabetes mellitus, asma brônquica, além de seu possível envolvimento na enxaqueca, na osteoporose, no alcoolismo, e nos distúrbios do sistema imunológico ${ }^{5}$.
O magnésio e o cálcio formam complexos estáveis com os fosfolípidios que fazem parte das membranas celulares. Dependendo da concentração de ambos, eles podem agir sinergisticamente ou antagonicamente. Assim, o magnésio é denominado "bloqueador natural do canal de cálcio". Na depleção de magnésio, o cálcio intracelular eleva-se. Visto que o cálcio exerce importante papel na contração tanto da musculatura lisa como da esquelética, um quadro de depleção de magnésio pode resultar em cãimbras musculares, hipertensão e vasoespasmos coronarianos e cerebrais 5 .

Mais da metade dos 21 a $28 \mathrm{~g}$ de magnésio encontrado no organismo fica armazenado nos ossos, sendo o restante distribuído entre a musculatura e os tecidos moles ${ }^{18}$. O magnésio é distribuído em compartimentos de trocas rápidas (coração, fígado, intestino, pele e outros tecidos conectivos) e de trocas lentas (ossos e musculatura esquelética). Nas situações nas quais a ingestão é adequada, os estoques de magnésio parecem ser mobilizados conforme demandas específicas dos sistemas corporais, ou seja, o magnésio transita lentamente entre os compartimentos ósseos, muscular e eritrocitário e apresenta rápida aparição no coração, no fígado, no intestino, na pele e em outros tecidos conectivos. Já nos casos de deficiência, os compartimentos de troca lenta suprem os órgãos vitais, como coração e fígado ${ }^{19}$.

A aferição do magnésio sérico, plasmático ou eritrocitário é o indicador do estado nutricional mais utilizado. A excreção urinária de magnésio é usada para avaliar o estado nutricional em magnésio, com um teste de sobrecarga, cujo método é considerado o mais confiável na detecção da deficiência de magnésio ${ }^{20}$. Por considerar os tecidos com maior concentração de magnésio no organismo, a determinação do conteúdo deste mineral no osso e no músculo reflete eficazmente suas reservas corporais. Todavia, as técnicas de obtenção de amostras de tecido no músculo e no osso são altamente invasivas e limitantes na pesquisa em humanos ${ }^{20}$. Os estudos de balanço também podem ser conduzidos, ainda que consistam de técnicas mais complexas e dispendiosas 5 . 
568 | A.G. AMORIM \& J. TIRAPEGUI

\section{Recomendações dietéticas e fontes alimentares de magnésio}

A Recomendação Dietética (Recommended Dietary Allowances - RDA) para o magnésio é de 400 a 420 e 310 a 320mg diários para homens e mulheres adultas, respectivamente. Todavia, grande número de pessoas em países industrializados consome menos do que o recomendado, havendo grande prevalência de deficiência dietética marginal de magnésio, fato que vem sendo associado a diversas doenças crônicas ${ }^{21}$.

A polêmica a respeito das Ingestões Dietéticas de Referência (Dietary Reference Intakes - DRI) para magnésio está no fato de os valores citados acima terem sido estabelecidos praticamente a partir de um único estudo. Nesse estudo22, para os homens, observou-se que a ingestão entre 204 e $595 \mathrm{mg} \mathrm{Mg} /$ dia era suficiente para manter o balanço entre 4 dos 9 homens estudados. Os 5 homens restantes não alcançaram balanço em magnésio. Dentre as 8 mulheres estudadas, 3 delas mantiveram o balanço em magnésio com a ingestão entre 213 e 304mg $\mathrm{Mg} / \mathrm{dia}$.

Na obtenção de mais dados a respeito das necessidades médias para o magnésio, Hunt \& Johnson ${ }^{23}$ analisaram os dados relativos ao balanço de magnésio de 27 estudos, todos conduzidos em unidades metabólicas e rigorosamente controlados. Seus resultados mostraram que o balanço do magnésio não é afetado pelo sexo ou pela faixa etária. Um balanço neutro para o magnésio (ou seja, ingestão magnésio = excreção magnésio) ocorre em pessoas sadias com uma ingestão de $165 \mathrm{mgMg} /$ dia. Considerando as Necessidades Estimadas (Estimated Average Requirement - EAR) estabelecidas atualmente, este valor de necessidade seria $40 \%$ a $45 \%$ menor para as mulheres e cerca de $50 \%$ menor para os homens. Este achado está de acordo com a idéia de as DRI estarem superestimadas. Moshfegh et al. ${ }^{24}$ observaram, entre 2001 e 2002, que, nos Estados Unidos, 64\% das pessoas com 51 a 70 anos não alcançaram as suas EAR para o magnésio $(265 \mathrm{mg}$ Mg/dia). No Brasil, encontrou-se $279 \mathrm{mg} / \mathrm{d}$ como consumo médio de magnésio para homens e mulheres adultos ${ }^{25}$.

No caso de roedores, as suas necessidades nutricionais estão estabelecidas. O oferecimento de $500 \mathrm{mg} \mathrm{Mg} / \mathrm{kg}$ ração é considerado o suficiente ${ }^{26}$, mesmo que em alguns trabalhos a ração controle fornecida apresentasse o dobro deste valor $^{27}$. Na maior parte dos estudos com animais o nível de deficiência de magnésio chega a apenas $10 \%$ do recomendado, sendo então classificada como grave. Este grau de deficiência não reflete o que ocorre em humanos com ingestão de magnésio abaixo do recomendado. Dessa forma, buscou-se realizar ensaios biológicos com animais submetidos à deficiência classificada como marginal28,29, na qual a ingestão de magnésio não representasse menos que $40 \%$ das recomendações.

Uma deficiência grave de magnésio está associada a doenças ou fatores condicionantes, como distúrbios na absorção intestinal ou na homeostase, ou ainda a casos de perdas excessivas de tecidos corporais, fluídos ou eletrólitos ${ }^{18}$. A deficiência grave de magnésio leva à hiperexcitabilidade muscular e a convulsões. Todavia, a deficiência marginal de magnésio em animais não manifesta os sinais clássicos de sua deficiência grave, mas sim em menor habilidade de lidar com o estresse, em mais danos cardíacos e vasculares e em mau funcionamento do organismo ${ }^{19}$.

Casos de toxicidade em magnésio ocorrem principalmente quando existe o consumo de suplementos farmacológicos. A UL estabelecida para o magnésio é de $350 \mathrm{mg} / \mathrm{d}$, considerando exclusivamente o consumo de suplementação farmacológica. A forma de manifestação inicial do consumo excessivo de magnésio por meio de fontes não alimentares é a diarréia5,20.

O magnésio é um mineral presente na maioria dos alimentos, em concentrações muito variadas; apresentando-se em altas concentrações 
nos vegetais escuros folhosos, bem como nas oleaginosas, nos cereais integrais e nas frutas secas $^{30}$. O consumo total de magnésio varia com o consumo energético, o que explica o consumo maior em jovens e homens adultos e valores menores em mulheres e em idosos 5 .

Em decorrência do elevado consumo energético entre atletas, alguns trabalhos relatam o consumo de magnésio igual ou acima das recomendações dietéticas na maioria dos indivíduos do sexo masculino ${ }^{31}$. Quanto às atletas, o consumo de magnésio é usualmente registrado menor que o recomendado. Além disso, independentemente do sexo, atletas participantes de atividades com categorias divididas pelo peso corporal (judô, boxe) ou com padrão estético rígido (balé, ginástica olímpica) tendem a consumir quantidades inadequadas de magnésio, por volta de $50 \%$ da recomendação ${ }^{17}$.

Os valores de consumo dietético de magnésio encontrados em atletas variam muito, indo de $345 \mathrm{mg} \mathrm{Mg} / \mathrm{d}$ em praticantes de musculação $0^{30} \mathrm{a}$ $684 \mathrm{mg} \mathrm{Mg} / \mathrm{d}$ em ciclistas em fase pré-competitiva $^{32}$.

\section{Magnésio na atividade física}

Os atletas, em particular, são um grupo populacional com tendência a apresentar perdas elevadas de magnésio pela urina e pelo suor em períodos de treinamento intenso. Inclusive, por esta razão, especula-se que as necessidades de atletas sejam $10 \%$ a $20 \%$ maiores do que as recomendações atuais para indivíduos sedentários de mesmo sexo e faixa etária ${ }^{6}$.

Vários trabalhos observaram se a suplementação de magnésio poderia melhorar a função celular. Entretanto, constatou-se que suplementação de magnésio não apresenta efeitos benéficos no desempenho físico quando o seu estado nutricional relativo estiver adequado. Desta forma, a suplementação de magnésio não apresenta efeitos ergogênicos, apenas reverte o estado da sua deficiência ${ }^{17}$.
A realização da atividade física leva à redistribuição do magnésio no organismo. $\mathrm{O}$ tipo de exercício e o seu estado nutricional influenciam a natureza desta redistribuição. Os primeiros estudos a respeito do assunto afirmavam que os exercícios de alta intensidade e de curta duração aumentam a concentração plasmática de magnésio em $5 \%$ a $15 \%$, retornando aos seus valores iniciais 24 horas após os exercícios. Esta alteração era associada com redução no volume plasmático ${ }^{20}$. Em estudos do final da década passada até hoje, a perda de massa muscular seria correspondente ao aumento do magnésio sérico logo após o exercício. Em contraste, no exercício prolongado ocorre redução da concentração sérica. Estes parâmetros geralmente retornam aos valores iniciais, provavelmente devido ao movimento do magnésio em direção a outros compartimentos e devido ao aumento da excreção pelo suor e urina. Dessa forma, o magnésio é redistribuído no exercício para os locais com maior necessidade metabólica para a produção de energia ou na prevenção do estresse oxidativo ${ }^{6}$.

O fluxo de magnésio ocorre durante e após o exercício físico. O magnésio transfere-se do soro em direção aos adipócitos e à musculatura esquelética ativa durante a atividade física (Figura 1A). O grau de passagem do magnésio extracelular para estes órgãos é modulado pelo nível de produção de energia aeróbia. Logo após o exercício aeróbio, ocorre redistribuição do magnésio dos tecidos para a circulação (Figura 1B). O magnésio é então mobilizado para o osso, para os tecidos moles, para o músculo e para o adipócito, com a finalidade de restaurar as concentrações de magnésio plasmático prévias ao exercício. O grau de dano muscular, que por sua vez é uma função da intensidade e duração da atividade realizada, é um fator na liberação de magnésio do músculo esquelético. Apesar de mecanismos de reabsorção tubular amenizarem as perdas de magnésio pela urina, a excreção de magnésio urinário após o exercício fica aumentada em relação à anterior ao exercício ${ }^{6}$. 
570 | A.G. AMORIM \& J. TIRAPEGUI

$1 \mathrm{~A}$
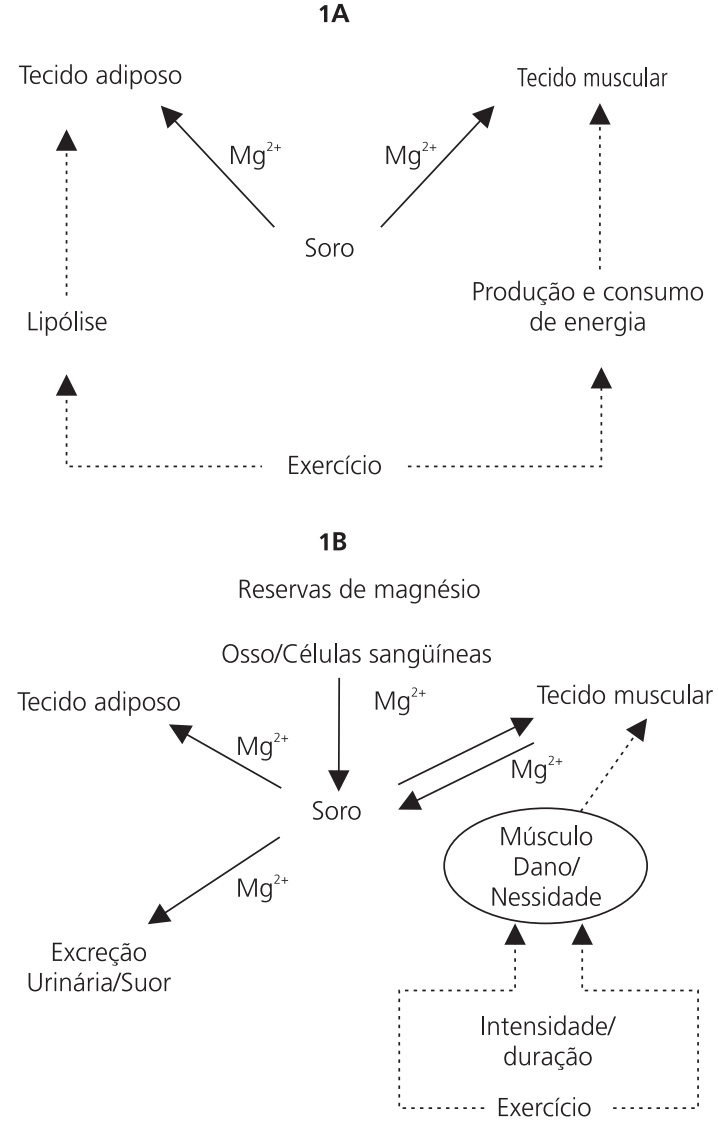

Figura 1. Fluxo de magnésio durante (1A) e após (1B) atividade física. As setas normais indicam o fluxo de magnésio. As setas pontilhadas mostram os fatores moduladores. Adaptado de Nielsen \& Lukaski6.

O magnésio participa da regulação da contração muscular pelo seu efeito direto no filamento pesado (miosina), na proteína regulatória (troponina), nas ATPases, no retículo sarcoplasmático e em outros pontos de armazenamento de cálcio ${ }^{19}$. O magnésio ainda atua no músculo inibindo a liberação de acetilcolina, o neurotransmissor que dá início à contração muscular. Dessa forma, a deficiência de magnésio no tecido muscular origina contrações musculares incontroláveis ${ }^{33}$.

Na mitocôndria, o conteúdo de magnésio corresponde a um terço do seu total na célula, estando ligado ao ATP e como um componente de membranas e dos ácidos nucléicos. Os íons de magnésio são cofatores necessários em subuni- dades da cadeia transportadora de elétrons mitocondrial e da piruvato desidrogenase fosfatase $^{34}$. Estas ações influenciam especificamente o exercício aeróbio, que depende da abundância de mitocôndria no músculo ${ }^{19}$.

\section{Deficiência de magnésio e estresse oxidativo no exercício físico}

Os mecanismos pelos quais a deficiência de magnésio leva ao estresse oxidativo ainda não estão completamente esclarecidos. Várias rotas metabólicas podem estar envolvidas na exacerbação da produção de radicais livres por meio da deficiência de magnésio.

É reconhecido que a deficiência de magnésio deixa as membranas celulares mais fluídas ${ }^{35}$. Tal fluidez em grandes proporções é um ponto chave nas alterações celulares que ocorrem na deficiência de magnésio ${ }^{36}$. No caso de atletas, os eritrócitos estão mais suscetíveis à hemólise, e a instalação da deficiência de magnésio reduz mais ainda a integridade celular, levando a um quadro de anemia. Tal anemia, mesmo que leve, vai prejudicar o desempenho físico ${ }^{37}$.

Na deficiência de magnésio, é observada maior atividade de canais de íon $\mathrm{Ca}^{2+}$ nas membranas do retículo sarcoplasmático, aumentando a saída do íon para o sarcoplasma, e, conseqüentemente, a sua concentração intracelular ${ }^{19}$. Além disso, este excesso de cálcio intracelular leva ao aumento no consumo de oxigênio e ATP e à hiperexcitabilidade, que pode causar câimbras musculares e fadiga ${ }^{6}$.

A enzima fosfolipase $A_{2}$ libera ácido araquidônico a partir de fosfolipídios, sendo ativada pelo aumento das concentrações intracelulares de cálcio. A ciclooxigenase reage com o ácido araquidônico para gerar o radical hidroxila ${ }^{3}$. Lerma et al. ${ }^{38}$ observaram que na deficiência de magnésio a proporção de ácido araquidônico na membrana de eritrócitos foi reduzida, por meio de mecanismos ainda não esclarecidos. Assim, o ácido araquidônico ficou mais disponível para a forma- 
ção de eicosanóides, colaborando para o aumento na suscetibilidade a lesões.

Calviello et al. ${ }^{39}$ relataram que a deficiência de magnésio foi acompanhada por diminuição nas defesas antioxidantes, no caso superóxido dismutase, glutationa reduzida e vitamina E hepáticas. Além disso, microssomas hepáticos de animais deficientes em magnésio mostraramse mais suscetíveis à peroxidação lipídica. Do mesmo modo, Freedman et al. ${ }^{40}$ também relataram que a deficiência de magnésio aumentou o dano oxidativo no coração de hamsters.

Em animais submetidos à dieta deficiente em magnésio a musculatura esquelética mostrou alterações no retículo sarcoplasmático e na mitocôndria. Houve maior produção ${ }^{41}$ de radicais $\mathrm{OH}^{-}$. Liu et al. ${ }^{42}$ observaram, em galinhas deficientes em magnésio, maior produção de espécies reativas de oxigênio e de malondialdeído na musculatura esquelética em comparação ao grupo controle, em detrimento da produção de glutationa. Na fração mitocondrial do músculo das aves deficientes em magnésio houve maior atividade de enzimas participantes da cadeia respiratória. Os autores especulam que, na deficiência de magnésio, a respiração celular acelera e a fosforilação é reduzida. O magnésio pode modular, ainda que parcialmente, a produção de espécies reativas de oxigênio.

O processo inflamatório costuma ser apontado como uma importante fonte de estresse oxidativo. A ocorrência do dano tecidual leva à maior concentração de interleucinas (IL), como IL-1, IL-6 e TNF- $\alpha$ na área afetada. Tais citocinas, por sua vez, sinalizam, por meio de moléculas de adesão, a infiltração de células polimorfonucleares ${ }^{43}$. Todavia, a resposta inflamatória pode ser potencializada pelo estresse oxidativo induzido pela deficiência de magnésio ${ }^{44}$. Weglicki et al. ${ }^{45}$ observaram, em ratos Sprague-Dawley deficientes em magnésio, aumento significativo nas concentrações das citocinas derivadas de células polimorfonucleares IL-1, IL-6 e TNF- $\alpha$ em relação ao grupo controle. A presença de macrófagos, neutrófilos ou eosinófilos em tecidos com baixas concentrações de magnésio aumentou a produção de radicais $\mathrm{O}_{2} "$-, facilitando a ocorrência de lesões teciduais. Como a deficiência de magnésio aumenta a produção de óxido nítrico ${ }^{46}$, e a atividade basal de neutrófilos ${ }^{47}$, ocorre maior produção do peroxinitrito. Mak et al. ${ }^{48}$ verificaram que no eritrócito de ratos deficientes em magnésio houve perda significativa de glutationa reduzida em relação aos animais do grupo controle, devido à superprodução de óxido nítrico e à ativação de neutrófilos. Recentemente, Scanlan et al. ${ }^{49}$ verificaram, no intestino de ratos, que a deficiência de magnésio não levou ao dano tecidual e não alterou a concentração do RNAm para o NFkB, família de fatores de transcrição implicados na regulação da resposta inflamatória. Entretanto, ocorreu exacerbação da infiltração de neutrófilos e da permeabilidade vascular.

A Figura 2 apresenta um esquema representativo do efeito da deficiência de magnésio no exercício físico, considerando aspectos do metabolismo oxidativo, podendo, inclusive, levar à apoptose. A deficiência de magnésio aumenta a concentração intracelular de íon $\mathrm{Ca}^{2+}$, facilitando a produção de ácido úrico e radical hidroxila. Este último pode ser produzido na presença de ferro a partir da reação de Fenton. A hidroxila também pode reagir com o óxido nítrico que está em grande concentração e formar peroxinitrito. Com a infiltração de neutrófilos na célula afetada pela deficiência de magnésio, a NAD(P)H oxidase mantémse ativa, produzindo superóxido. Estes eventos levam a perturbações na estabilidade das membranas, facilitando o dano tecidual. Na persistência deste quadro, a apoptose pode ocorrer. Pode haver, também, comprometimento da função muscular, do mecanismo da contração e da atividade de enzimas do metabolismo energético, prejudicando, em conjunto com os outros fatores aqui citaos, o desempenho físico. A resposta inflamatória é maior na deficiência de magnésio, sugerindo a existência de um ciclo vicioso entre este, inflamação e estresse oxidativo, que, no desempenho físico, traduz-se em lesões musculares mais sérias. 


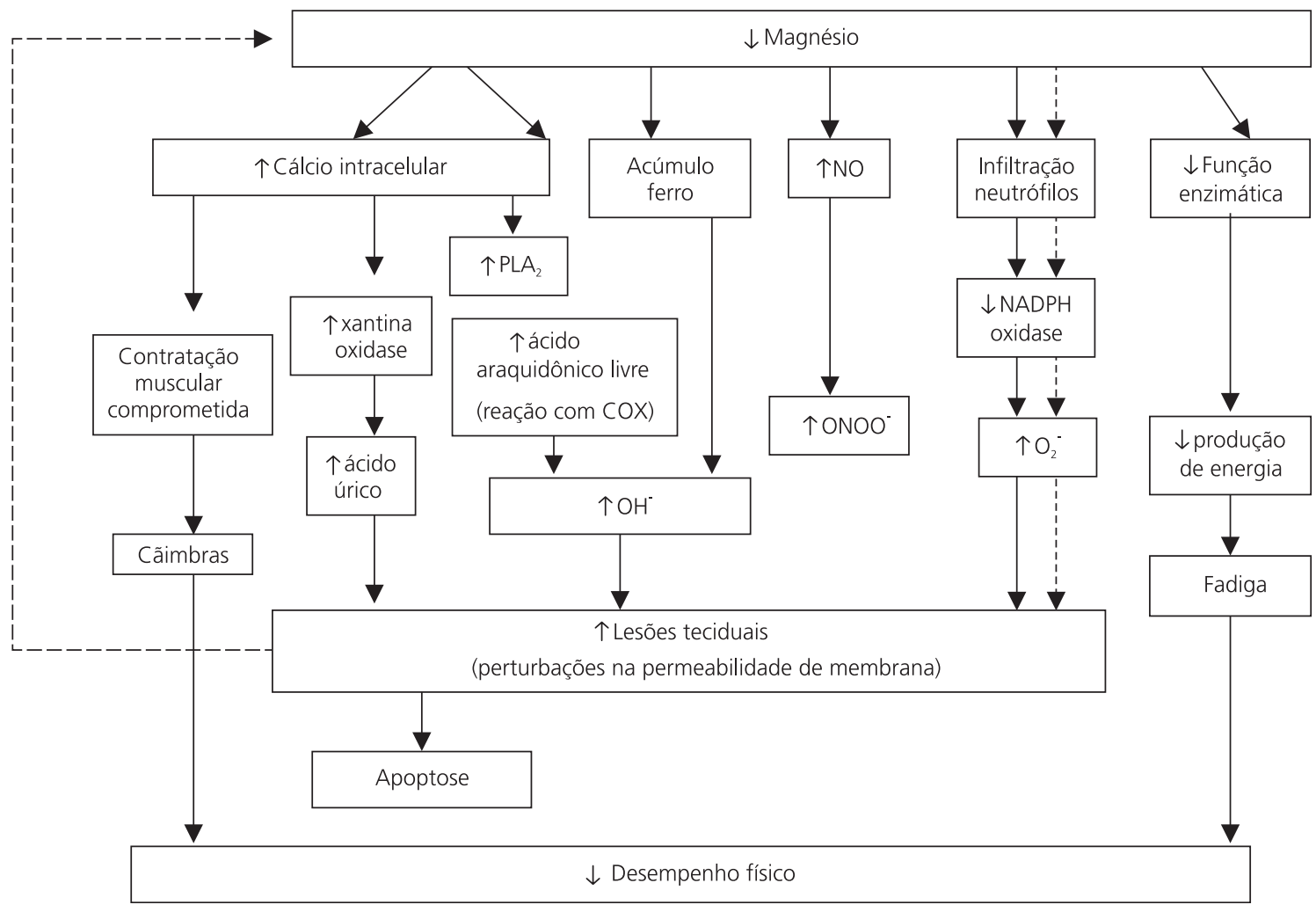

Figura 2. Possíveis mecanismos pelos quais o estresse oxidativo induzido pela deficiência de magnésio prejudica o desempenho físico. Nota: Este processo pode eventualmente levar a apoptose. Também é desencadeado um ciclo vicioso entre deficiência de magnésio, inflamação e estresse oxidativo (setas pontilhadas). $\uparrow$ : aumento, $\downarrow$ : diminuição, NO: óxido nítrico, $\mathrm{O}_{2}:$ radical superóxido, ONOO-: peroxinitrito, $\mathrm{OH}^{-}$ radical hidroxil, COX: ciclooxigenase, PLA ${ }_{2}$ : prostaglandina $\mathrm{A}_{2}$.

Apesar das evidências, o estresse oxidativo induzido pela deficiência de magnésio pouco é estudado no âmbito da atividade física. Monteiro et al..$^{50}$ observaram, no sangue de portadores de Síndrome de Down que fizeram treinamento aeróbio por 16 semanas, maior atividade da superóxido dismutase no eritrócito e concentrações de substâncias reativas ao ácido tiobarbitúrico (TBARS) plasmáticos menores em relação ao grupo controle. As concentrações de magnésio eritrocitário permaneceram menores após o treinamento. Em outro estudo, Laires et al. ${ }^{51}$ analisaram o sangue de corredores 3 minutos antes e após uma corrida de 40 minutos. Não foram encontradas diferenças significativas entre parâmetros de estresse oxidativo e da capacidade antioxidante. Já Leal et al. ${ }^{52}$ verificaram, em jogadores de futebol profissionais submetidos a 7 dias de suplementação de magnésio, que os valores de TBARS e de magnésio sérico diminuíram após teste em bicicleta ergométrica, sendo o magnésio capaz de exercer algum efeito indireto no estresse oxidativo induzido pelo exercício. Recentemente, Amorim et al. ${ }^{53}$ encontraram, na musculatura de ratos submetidos a $40 \%$ de deficiência de magnésio e ao exercício físico, menor atividade da superóxido dismutase e da glutationa peroxidase

\section{CONSIDERAÇÕ ES FIN A IS}

No contexto da atividade física, o conhecimento da relação entre magnésio e estresse oxidativo é escasso e controverso. A deficiência de magnésio aumenta a produção de radicais livres, levando a alterações nas membranas celulares e a aumento na concentração de cálcio intracelular. Este aumento dificulta a contração muscular e ativa enzimas importantes na produção 
de eicosanóides. A ação conjunta desses mecanismos facilita a suscetibilidade a lesões e, conseqüentemente, prejudica o desempenho. A deficiência de magnésio também aumenta a produção de óxido nítrico e a ocorrência de infiltração celular por células polimorfonucleares. A resposta inflamatória é aumentada na deficiência de magnésio, sugerindo a existência de um ciclo vicioso entre este, inflamação e estresse oxidativo, que, no desempenho físico, traduz-se em lesões musculares mais sérias. Apesar de o número de estudos sobre este tema ter aumentado nos últimos 15 anos, vários tópicos relativos ao assunto precisam ser esclarecidos. Não se sabe até o momento, por exemplo, se a deficiência marginal de magnésio tem os mesmos efeitos sobre o metabolismo oxidativo que a deficiência grave. Além disso, ainda precisa ser melhor definida a função das defesas antioxidantes na prática regular de exercício físico e na deficiência de magnésio.

\section{A GRADECIMENTOS}

À Coordenação de Aperfeiçoamento de Pessoal de Nível Superior (CAPES) pela bolsa de pesquisa outorgada.

\section{COLABORADORES}

Ambos os autores participaram da concepção e da redação do trabalho.

\section{REFER Ê N CIAS}

1. Powers SK, Lennon S. Analysis of cellular responses to free radicals: focus on exercise and skeletal muscle. Proc Nutr Soc. 1999; 58(4):1025-34.

2. Finaud J, LaC G, Filaire E. Oxidative stress. Relationship with exercise and training. Sports Med. 2006; 36(4):327-58.

3. Schneider CD, Oliveira AR. Radicais livres de oxigênio e exercício: mecanismos de adaptação ao treinamento físico. Rev Bras Med Esp. 2004; 10(4):308-13.

4. Halliwell B. Reactive species and antioxidants. Redox biology is a fundamental theme of aerobic life. Plant Physiol. 2006; 141(3):312-22.
5. Food and Nutrition Board, Institute of Medicine. Magnesium. In: Dietary references intakes of calcium, magnesium, phosphorus, vitamin D, and fluoride. [cited 2000 Feb 25]. Washington (DC): National Academy Press; 1997. Available from: <http://www.nap.edu/openbook/0309063507/ html/R1.html>.

6. Nielsen FH, Lukaski HC. Update on the relationship between magnesium and exercise. Magnes Res. 2006; 19(3):180-9.

7. Valko M, Leibfritz D, Moncol J, Cronin NTD, Mazur $\mathrm{M}$, Telser J. Free radicals and antioxidants in normal physiological functions and human disease. Int J Biochem Cell Biol. 2007; 39(1):44-84.

8. Clanton TL, Zuo L, Klawitter P. Oxidants and skeletal muscle function: physiologic and pathophysiologic implications. Proc Soc Exp Biol Med. 1999; 222(3): 253-62.

9. Smith MA, Reid MB. Redox modulation of contractile function in respiratory and limb skeletal muscle. Resp Physiol Neurobiol. 2006; 151(2-3): 229-41.

10. Vollard NBJ, Shearman JP, Cooper CE. Exerciseinduced oxidative stress. Myths, realities and physiological relevance. Sports Med. 2005; 35(12): 1045-62.

11. Cooper CE, Vollaard NB, Choueiri T, Wilson MT. Exercise, free radicals and oxidative stress. Biochem Soc Trans. 2002; 30(2):280-4.

12. Uchiyama S, Tsukamoto H, Yoshimura S, Tamaki T. Relationship between oxidative stress in muscletissue and weight-lifting-induced muscle damage. Pflugers Archiv, Eur J Physiol. 2006; 452(1): 109-16.

13. Touyz RM, Schiffrin EL. Reactive oxygen species in vascular biology: implications in hypertension. Histochem Cell Biol. 2004; 122(4):339-52.

14. Reid MB. Plasticity in skeletal muscle, and smooth muscle. Invited review: redox modulation of skeletal muscle contraction: what we know and what we don't. J Appl Physiol. 2001; 90(2): 724-31.

15. Close GL, Kayani A, Vasilaki A, Mcardle A. Skeletal muscle damage with exercise and aging. Sports Med. 2005; 35(5):413-27.

16. Sureda A, Tauler P, Aguilo A, Cases N, Fuentespina $E$, Córdova $A$, et al. Relation between oxidative stress markers and antioxidant endogenous defences during exhaustive exercise. Free Rad Res. 2005, 39(12):1317-24.

17. Lukaski HC. Vitamin and mineral status: effects on physical performance. Nutrition. 2004; 20(7-8): 632-44. 
574 | A.G. AMORIM \& J. TIRAPEGUI

18. Saris NL, Mervaala E, Karppanen H, Khawaja JÁ, Lewenstam A. Magnesium: an update on physiological, clinical, and analytical aspects. Clin Chem Acta. 2000; 294(1-2):1-26.

19. Brilla LR, Lombardi VP. Magnesium in sports physiology and performance. In: Wolinski I, Driskell $A$, editors. Sports nutrition: minerals and electrolytes. Boca Raton: CRC Press; 1995.

20. Bohl CH, Volpe SL. Magnesium and exercise. Crit Rev Food Sci Nutr. 2002; 42(6):533-63.

21. Ford ES, Mokdad AH. Dietary magnesium intake in a national sample of U.S. adults. J Nutr. 2003; 133(9):2879-82.

22. Lakshmanan FL, Rao RB, Kim WW, Kelsay JL. Magnesium intakes, balances, and blood levels of adults consuming self-selected diets. Am J Clin Nutr. 1984; 40(Suppl 6):1380-9.

23. Hunt CD, Johnson LK. Magnesium requirements: new estimations for men and women by crosssectional statistical analyses of metabolic magnesium balance data. Am J Clin Nutr. 2006; 84(4):843-52.

24. Moshfegh A, Goldman J, Cleveland L. What we eat in America, NHANES 2001-2002: usual nutrient intakes from food compared to dietary reference intakes. [cited 2007 Feb 5]. Available from: <http://www.ars.usda.gov/SPUser Files/Place/ 12355000/pdf/usualintaketables2001-02.pdf>.

25. Yuyama LKO, Rocha YR, Cozzolino SMF. Composição química e percentual de adequação da dieta regional de Manaus, AM. Acta Amazônica. 1992; 22(4):587-93.

26. Reeves PG, Nielsen FH, Fahey Jr GC. AIN-93G purified diets for laboratory rodents: final report of the American Institute of Nutrition ad hoc writing Committee on the reformulation of the AIN-76A rodent diet. J Nutr. 1993; 123(11): 1939-51.

27. Rude RK, Gruber HE, Norton HJ, Wei LY, Frausto A, Kilburn J. Dietary magnesium reduction to $25 \%$ of nutrient requirement disrupts bone and mineral metabolism in the rat. Bone. 2005; 37(2):211-9.

28. Feillet-Coudray C, Coudray C, Tressol JC, Pépin D, Mazur A, Abrams SA, et al. Exchangeable magnesium pool masses in healthy women: effects of magnesium supplementation. Am J Clin Nutr. 2002; 75(1):72-8.

29. Feillet-Coudray C, Trzeciakiewicz A, Coudray C, Rambeau M, Chanson A, Rayssiguier $Y$, et al. Erythrocyte magnesium fluxes in mice with nutritionally and genetically low magnesium status. Eur J Nutr. 2006; 45(1):171-7.

30. Amorim AG. Magnésio na dieta de praticantes de musculação [dissertação]. São Paulo: Faculdade de
Ciências Farmacêuticas, Universidade de São Paulo; 2002.

31. Kleiner SM, Bazarre TL, Litchford MD. Metabolis profiles, diet, and health practices of championship male and female bodybuilders. J Am Diet Assoc. 1990; 90(7):962-7.

32. Jensen CD, Zaltas ES, Whittam JH. Dietary intakes of male endurance cyclists during training and racing. J Am Diet Assoc. 1992; 92(8):986-8.

33. Johnson S. The multifaceted and widespread pathology of magnesium deficiency. Med Hipoth. 2001; 58(2):163-70.

34. Ames BN, Atamma H, Killilea DW. Mineral and vitamin deficiencies can accelerate the mitochondrial decay of aging. Mol Aspects Med. 2005; 26(4-5):363-78.

35. Freedman AM, Mak IT, Stafford RE, Dickens BF, Cassidy MM, Muesing RA, et al. Erythrocytes from magnesium-deficient hamsters display an enhanced susceptibility to oxidative stress. Am J Physiol. 1992; 262(6):C1371-5.

36. Astier C, Rock E, Lab C, Gueux E, Mazur A, Rayssiguier $Y$. Functional alterations in sarcoplasmatic reticulum membranes of magnesium-deficient rat skeletal muscle as consequences of free radicalmediated process. Free Rad Biol Med. 1996; 20(5):667-74.

37. Rayssiguier Y, Guezennec CY, Durlach J. New experimental and clinical data on the relationship between magnesium and sports. Magnes Res. 1990; 3(2):93-102.

38. Lerma A, Planells E, Aranda P, Llopis J. Effect of magnesium deficiency on fatty acid composition of the erytrhocyte membrane and plasma lipid concentration in rats. J Nutr Biochem. 1995; 6(11):577-81.

39. Calviello G, Ricci P, Lauro L, Palozza P, Cittadini A. $\mathrm{Mg}$ deficiency induces mineral content changes and oxidative stress in rats. Biochem Mol Biol Int. 1994; 32(5):903-11.

40. Freedman AM, Cassidy MM, Weglicki WB. Magnesium-deficient myocardium demonstrates an increased susceptibility to an in vivo oxidative stress. Magnes Res. 1991; 4(3-4):185-9.

41. Rock E, Astier C, Lab C, Vignon X, Gueux E, Motta $C$, et al. Dietary magnesium deficiency in rats enhances free radical production in skeletal muscle. J Nutr. 1995a; 125(6):1205-10.

42. Liu YX, Guo YM, Wang Z. Effect of magnesium on reactive oxygen species production in the thigh muscles of broiler chickens. Br Poultry Sci. 2007; 48(1): 84-9. 
43. Cannon JG, ST Pierre BA. Cytokines in exertioninduced skeletal muscle injury. Mol Cell Biochem. 1998; 179(1):159-67.

44. Mazur A, Maier JAM, Rock E, Gueux E, Nowacki W, Rayssiguier $Y$. Magnesium and the inflammatory response: potencial physiopathological implications. Arch Biochem Biophys. 2007; 458(1):48-56.

45. Weglicki WB, Phillips TM, Freedman AM, Cassidy MM, Dickens BF. Magnesium deficiency elevates circulating levels of inflammatory cytokines and endothelin. Mol Cell Biochem. 1992; 110(2): 169-73.

46. Rock E, Astier C, Lab C, Malpuech C, Nowacki W, Gueux $E$, et al. Magnesium deficiency in rats induces a rise in plasma nitric oxide. Magnes Res. 1995b; 8(3):237-42.

47. Mak IT, Dickens BF, Komarov AM, Wagner TL, Phillips TM, Weglicki WB. Activation of the neutrophil and loss of plasma glutathione during magnesium deficiency: modulation by nitric oxide synthase inhibition. Mol Cell Biochem. 1997; 176(1-2):35-9.

48. Mak IT, Komarov AM, Wagner TL, Stafford RE, Dickens BF, Weglicki WB. Enhanced NO production during $\mathrm{Mg}$ deficiency and its role in mediating red blood cell glutathione loss. Am J Physiol. 1996; 271(1 Pt 1):C385-90.

49. Scanlan BJ, Tuft B, Elfrey JE, Smith A, Zhao A, Morimoto $M$, et al. Intestinal inflammation caused by magnesium deficiency alters basal and oxidative stress-induced intestinal function. Mol Cell Biochem [e-journal] 2007 [cited 2007 Aug. 11]. Available from: <http://www.springerlink.com>.

50. Monteiro CP, Varela A, Pinto M, Neves J, Felisberto GM, Vaz C, et al. Effect of an aerobic training on magnesium, trace elements and antioxidant systems in a Down syndrome population. Magnes Res. 1997; 10(1):65-71.

51. Laires MJ, Madeira F, Sergio J, Colaco C, Vaz C, Felisberto GM, et al. Preliminary study of the relationship between plasma and erythrocyte magnesium variations and some circulating prooxidant and antioxidant indices in a standardized physical effort. Magnes Res. 1993; 6(3):233-8.

52. Leal L, Gómez-Trullen E, Gálvez M, López-Colón JL, Millán S, García J, et al. Mg-supplementation in soccer players: effects on metal related to antioxidant defence. Magnes Res. 2004, 17(3): 230.

53. Amorim AG, Pires ISO, Tirapegui J. Indicators of oxidative stress in rats submitted to physical training and to a magnesium-deficient diet. Procedings of the 54th Annual Meeting of the American College of Sports Medicine; 2007 Jun; New Orleans, USA; 2007. Med Sci Sports Exerc. 2007; 39(Suppl 1):S292.

Recebido em: 26/4/2007

Versão final reapresentada em: 25/9/2007

Aprovado em: 28/5/2008 